\title{
SARAU ARTE DE SINALIZAR: NARRATIVA, HUMOR E POESIA
}

\author{
$* * *$ \\ ART OF SIGNING POETRY SLAM: NARRATIVES, HUMOUR AND \\ POETRY
}

Cláudio Henrique Nunes Mourão ${ }^{1}$ Bruna da Silva Branco ${ }^{2}$

Recebimento do texto: 17/04/2018

Data de aceite: 20/05/2018

RESUMO: Neste artigo, são apresentadas as impressões de espectadores do evento cultural "Sarau Arte de Sinalizar: narrativa, humor e poesia", que ocorreu em Porto Alegre - RS, vinculado ao projeto de extensão da Universidade Federal do Rio Grande do Sul. A ideia de promover esse encontro, em forma de Sarau, veio da própria comunidade surda, que objetivava compartilhar e registrar diferentes maneiras culturais da arte de sinalizar. O palco do Sarau contou com artistas surdos brasileiros e apresentações em vários gêneros literários. Nesse evento, foram realizadas entrevistas com os espectadores, que objetivaram explicitar as experiências ali constituídas. Os depoimentos bem relevantes à apresentação de resultados produzidos a partir das experiências do outro, registrados e conectados a um fluxo compartilhado com a Literatura Surda e os Estudos Surdos.

PALAVRAS-CHAVE: Língua Brasileira de Sinais; Cultura Surda; Literatura Surda.

ABSTRACT: This article will present the spectator's impressions towards the cultural event "Art of Signing Poetry Slam: narrative, humour and poetry", which took place in Porto Alegre - RS, linked to the University Extension Program of the Universidade Federal do Rio Grande do Sul. The idea of this event, in the shape of a poetry slam, came from the deaf community itself, and aimed to share and register the cultural differences in the art of signing. The poetry slam stage received brazilian deaf artists performing several literature genres. In the event, was also made interviews with the spectators, aiming the make explicit the experiences built in it. The testimonials were extremely important to understand the results produced by said experience from each of the spectators, registered and connected to a cofluence with the Deaf Literature and Deaf Studies.

KEYWORDS: Brazilian Sign Language; Deaf Culture; Deaf Literature.

\footnotetext{
${ }^{1}$ Doutor em Educação. Professor Adjunto no Instituto de Letras, Departamento de Línguas Modernas, no Curso de Bacharelado em Letras, habilitação Tradutor e Intérprete de Libras-Português/Português-Libras, na Universidade Federal do Rio Grande do Sul (UFRGS). E-mail: claudiomourao@gmail.com

${ }^{2}$ Bolsista da CAPES e mestranda no Programa de Pós-Graduação em Educação (PPGEdu) na Universidade Federal Rio Grande do Sul (UFRGS).E-mail: bruninha_branco18@ hotmail.com
} 
Introdução

Este artigo centra um olhar nas produções das mãos literárias no evento cultural Sarau Arte de Sinalizar. A ideia de promover esse encontro, ocorrido na forma de sarau, surgiu das demandas e expectativas da própria comunidade surda, que tinha por objetivo compartilhar e registrar diferentes maneiras culturais da arte de sinalizar. O trabalho é inspirando a partir de estudos produzidos no campo dos estudiosos vinculados aos Estudos Culturais e Estudos Surdos, produzidos por pesquisadores da Literatura Surda, tal como Lodenir Karnopp (2006, 2010), Ronice Quadros e Rachel Sutton-Spence (2006), Karin Strobel (2008), Carolina Hessel Silveira (2015), Rosa Hessel Silveira (2004), Madalena Klein e Fabiano Rosa (2011), Cláudio Mourão (2011, 2016), entre outros.

O projeto de extensão Arte de Sinalizar, em conjunto com a equipe da Universidade Federal do Rio Grande do Sul (UFRGS) e comissões externas que tiveram experiência no campo de Estudos Surdos e Literatura Surda, teve por objetivo dar continuidade às pesquisas e registros de Literatura Surda, bem como a circulação de informações para outros participantes interessados em conhecer gêneros literários produzidos pela comunidade surda. No desenvolvimento da pesquisa compreendemos a relevância do papel para nós foi o papel social da academia enquanto meio de registro e divulgação de uma biblioteca literária.

O que pretendemos com este artigo é mostrar nossa interpretação do espaço cultural, analisando e compreendendo processos de subjetivação vivenciados por sujeitos surdos produzidas a partir da experiência e da transformação, vislumbrando as marcas deixadas na história e criando novos registros em todos os sentidos, entre os

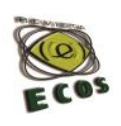

Revista Ecos vol.24, Ano 15, nº1 (2018) 
espectadores e as mãos literárias presentes no palco, às quais expressam seu pertencimento à Literatura Surda e à comunidade surda. As análises realizadas foram feitas a partir de entrevistas com esses espectadores, as quais objetivam explicitar as experiências no espaço cultural no Sarau. Esses depoimentos foram relevantes para a apresentação de resultados produzidos a partir das experiências do outro, registradas e conectadas a um fluxo compartilhado com a Literatura Surda e os Estudos Surdos.

\section{Experiências e histórias das mãos literárias...}

O dia 24 de abril é celebrado como o Dia Nacional da Língua da Brasileira de Sinais (Libras), em função da Lei de Libras, nº 10.436 de 24 de abril de 2002, que em 2017 completou 15 anos desde que foi sancionada. Coincidentemente, não deixando de registrar essa data tão importante, neste dia realizamos o evento cultural "Sarau Arte de Sinalizar: narrativa, humor e poesia", o primeiro Sarau da comunidade surda em Porto Alegre. O evento foi promovido pelos idealizadores Arte de Sinalizar é um projeto de extensão, da Faculdade de Educação da UFRGS.

Sabemos que há uma longa história que nos permite compreender os significados das mãos literárias, transmitidas em língua de sinais, de geração em geração pelo próprio o povo surdo. As mãos literárias assumem um significado dentro da Literatura Surda (MOURÃO, 2016). Nessa trajetória de mais de um século, a maioria dos sujeitos surdos - tanto crianças quanto adultas -, não tinha acesso à escola de surdos e/ou bilíngues para surdos, eram apenas colocados em uma mesma caixa, a escola convencional, onde há a forte presença do limitado e desconhecido território da língua oficial do país na sua produção oral e escrita. Em compensação, existem os

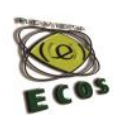

Revista Ecos vol.24, Ano 15, nº1 (2018) 
territórios das mãos, que ocorrem por meio do encontro dos sujeitos surdos, os mais velhos transmitindo as mãos literárias para os sujeitos jovens e crianças surdas, mostrando efeitos significativos literários, por intermédio dos quais foram mantidas vivas as memórias através dos olhos, uma pátria de mãos, ricas e de variadas culturas surdas.

Segundo Mourão (2016, p. 50), a partir de um exemplo que pesquisador surdo estadunidense Benjamin Bahan (2006), que entrevistou um surdo estadunidense Gilbert Eastman, descrevendo sua experiência de encontros dos surdos no grupo de escoteiros.

\begin{abstract}
(...) na década 1940, quando estudava na Escola Americana para Surdos (ASD),em Hartford, que lembra vividamente da visualiterária, com admiração pelas crianças mais velhas contadores de várias histórias, especialmente quando ele era um escoteiro. Eastman conta que os escoteiros surdos iam acampar todos os anos e à noite se reuniam em torno da fogueira no "Fogo do Conselho", para contar histórias e partilhar entre eles. Os escoteiros surdos mais velhos contavam e recontavam histórias de mistério, de fantasmas, cenas de filmes, experiência, piadas, brincadeiras e histórias com jogos do alfabeto manual.
\end{abstract}

No Brasil, Flausino José da Gama, ex-aluno e profissional repetidor (denominado como primeiro professor surdo) do Imperial Instituto dos Surdos-Mudos, publicou um livro com sinais desenhados intitulado "Iconographia dos signaes dos surdos-mudos" no ano de 1875 (ROCHA, 2010). Segundo Mourão (2016), além do professor acompanhar a rotina de aula dos alunos, também os observava nos corredores, intervalos e até pernoitava com eles. Há relatos que Flausino sinalizava obras de literatura para alunos surdos, que podem ter sido narrativas, anedotas, piadas ou mesmo informações da rotina social. Assim, quando os alunos do instituto voltavam para a sua 
região de origem, espalhavam essas histórias, divulgadas entre os olhos e as mãos da comunidade surda. Esses espaços de encontro de surdos são comumente descritos como escolas de surdos, esportes, bares, praias, colônia de férias etc., nos quais há circulação e consumo dessas literaturas, produzidas por mãos literárias, em vários gêneros, circulando na comunidade surda - apesar de muitas dessas histórias não estarem registradas.

Podemos ver que essas produções estão relacionadas à Literatura Surda, em um processo significativo da literatura da forma visualiterária, que transmite os significados das mãos literárias: um processo sem fim, produzido em vários gêneros literários. (MOURÃO, 2016). Conforme Mourão (2016, p. 19) o conceito da visualiterária é compreendido como:

\footnotetext{
[...] referir aos textos literários em línguas de sinais, na modalidade visual dessa língua. Penso que o termo "visualiterária" valoriza a visualidade do povo surdo e produz significados em sinais, utilizando recursos estéticos e a arte de sinalizar.
"Na segunda metade do século XX e no século XXI, a oralidade começa a ser novamente valorizada e observa-se um encaminhamento no estudo dos gêneros literários o qual consegue abarcar as performances orais [...].”. (GOLDEMERG; CUNHA, 2010, P. 118).

Na linha do tempo, há conflitos de significados e conceituações sobre literatura, pois havia a tentativa de padronização com a literatura ocidental, ou seja, pregando uma "tradição ocidental".

Deborah Goldemberg (2009, p. 54) organizou um sarau de poesias indígenas, mas recebeu críticas de uma pessoa da instituição, que disse o seguinte: "Do que vocês estão falando? Não existe poesia indígena, nem literatura indígena! Poesia e literatura 
são coisas da tradição ocidental, aristotélica. Vocês não sabem do que estão falando!”. Assim como nessa situação apresentada pela autora, há pessoas que não acreditam na existência de Literatura Surda; contudo, sustentamos que a Literatura Surda é a arte de sinalizar, uma forma de os sujeitos surdos se constituírem e produzirem significados por meio de suas mãos literárias; uma maneira viver, sentir, compreender, respirar e significar sua língua e cultura. Sobre isso, Karnopp (2010, p. 161) aponta que:

\footnotetext{
Literatura surda é a produção de textos literários em sinais, que traduz a experiência visual, que entende a surdez como presença de algo e não como falta, que possibilita outras representações de surdos e que considera as pessoas surdas como um grupo linguístico e cultural diferente.
}

Neste sentido, a Literatura Surda está presente em vários gêneros literários através dos quais adquirem a visualiterária que transmite os significados literários, adquirido pelos olhos do povo surdo, produzidos e consumidos em língua de sinais, traduzidos por meio de artefatos próprios da cultura surda. Pelas mãos literárias, são produzidos diversos gêneros literários, como a contação de histórias e poesias em língua de sinais. Segundo John Flow (2007 apud GOLDEMBERG; CUNHA, 2010), este é um conceito que conecta gênero literário e performance; portanto, trata-se de uma estrutura performática.

[...] os gêneros geram formatam ativamente o conhecimento do mundo, a fim de que se tornem "uma forma de ação simbólica: a organização genérica da língua, imagem, gestos e som faz com que as coisas aconteçam ao formatar ativamente a maneira como entendemos o mundo" (FLOW, 2007, p. 2 apud GOLDEMBERG; CUNHA, 2010, p. 119)

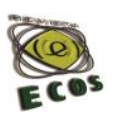

Revista Ecos vol.24, Ano 15, nº1 (2018) 
No contexto da Literatura Surda, entendemos que povo surdo conecta suas mãos literárias, que constituem formas de compreender e de vivenciar a literatura por meio da sinalidade, em vários gêneros literários. Sinalidade é produção linguística em sinais dos surdos, assim como o termo oralidade é tradicionalmente utilizado para o ouvinte (MOURÃO, 2011, p. 19). Nesse sentido, o Sarau Arte de Sinalizar propicia aos participantes e sujeitos surdos se expressarem com suas mãos literárias de forma performática literária. Sobre isso, Goldemberger (2010, p. 121) afirma o seguinte:

\begin{abstract}
Apesar de muitos dos participantes do Sarau transmitirem sua literatura através do registro escrito, nosso objetivo é foca lizar como o texto literário funciona enquanto performance, e a importância de um fenômeno cultural como o Sarau como espaço de expressão de tais performances.
\end{abstract}

O autor menciona o registro durante a realização de tipo de evento, e esse foi um dos motivos que inspiraram a criação do Sarau. Entendemos que para a expressão das mãos literárias e a valorização a língua de sinais, é fundamental o resgate das nossas histórias e a sobrevivência da cultura surda brasileira. Segundo Karnopp, Klein e Lunardi-Lazzarin (2011, p. 20), “[...] a cultura do reconhecimento é de importância crucial para as minorias linguísticas que desejam afirmar suas tradições culturais e recuperar suas histórias reprimidas.”.

\title{
O Sarau...
}

Segundo o Dicionário Online de Português ${ }^{i}$, o significado de Sarau é o seguinte: "O conjunto de pessoas que se reúnem para fazer atividades recreativas como: ouvir músicas, recitar poesias, conversar etc; Show ou concerto musical que ocorre durante a noite; Reunião literária noturna”. A palavra Sarau origina-se do latim seranus, 
relativo ao anoitecer, tardio. Segundo os sites consultados, o sarau é um evento cultural onde as pessoas se encontram para se expressam artisticamente. Em um Sarau comumente se reúnem amigos, em casa ou em outro espaço, como um ponto de encontro, um clube, um teatro, um festival, em bares, em praças públicas; O foco do sarau está na temática central: compartilhar as suas ideias, realizar apresentações individuais ou em grupo, interpretações ou performances artísticas e literárias, vinculadas a suas efetividades e emoções.

Hoje em dia, os Saraus estão presentes em vários eventos culturais, tanto os abertos ao público quanto em lugares privados. No site eletrônico chamado Sarau Benedito ${ }^{\mathrm{ii}}$, consta o seguinte:

\footnotetext{
Sarau Literário: Um grupo formado para aqueles que querem expor seus textos ao público, discutir literatura (acadêmica ou leigamente) e conhecer um pouco mais da história dessa arte que nos traz tanta emoção e vivacidade aos nossos olhos! Os Saraus eram manifestações artísticas de teatro, dança, música e poesia que eram apresentadas para os nobres e reis.
}

Assim como realizamos o Sarau Arte de Sinalizar, o objetivo segue o mesmo: promover um encontro para a comunidade surda compartilhar e registrar diferentes formas culturais da arte de sinalizar. Segundo o coordenador Cláudio Mourão, o projeto de Arte de Sinalizar busca oferecer espaço no Sarau para a comunidade surda, possibilitando que artistas/autores surdos se apresentem no palco e compartilhem suas produções com o público. O Sarau é como que o resultado de registros, descobertas e interações das mãos literárias, que conecta público e artistas que se sentiram tão valorizados no espaço surdo, cultura e língua. Um breve histórico que possibilitará aos

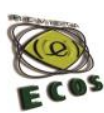

Revista Ecos vol.24, Ano 15, nº1 (2018) 
leitores reconhecer o valor e o desempenho das mãos dos responsáveis pelas comissões organizadoras do Sarau.

O evento contou com uma equipe da UFRGS, composta por surdos e ouvintes, professores e intérpretes da língua de sinais. Na comissão organizadora, a maioria surdos e pessoas externas, pois acreditamos na competência e no desempenho de quaisquer surdos, incentivando os jovens da comissão a ter um futuro profissional. Foram eles que criaram as ideias e compartilharam informações para o desenvolvimento de aprendizagens em artes e culturas. Por outro lado, houveram cinco alunos no curso de Letras/Libras, na modalidade Educação a Distância pela Universidade Federal de Santa Catarina (UFSC), no polo Instituto Federal Farroupilha (IFFar), campus Santa Rosa-RS, residentes de Porto Alegre e Caxias do Sul-RS.

Os acadêmicos surdos dos cursos de design, desenho, recursos humanos e amadores/atores-atrizes/líderes, constantemente estavam convivendo com sujeitos surdos, em momentos que envolviam bate-mãos (o termo bate-papo na língua oral), inúmeras risadas e diversas situações emotivas, bem como estudos para criar as ideias de literária (que consta numa disciplina Literatura Surda). Surgindo assim o compartilhamento recheado de efeitos e espontaneidade, que transmitem significativas literaturas, produzidas e expressas por mãos literárias.

Para tanto, a ideia foi de atrair os jovens surdos acadêmicas a fazerem parte da comissão organizadora do Sarau Arte de Sinalizar e conduzir equipes de voluntários. O trabalho constitui e integra a representação da comunidade surda, incentivando os registros da história e sobrevivência da cultura surda. A um Sarau pode atribuir-se relevantes pesquisas, pois acreditamos que a valorização da comunidade surda imbuída de uma rica área, a Literatura Surda Brasileira, pode nos trazer esses resultados. Para

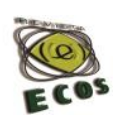

Revista Ecos vol.24, Ano 15, nº1 (2018) 
iniciar divulgação, seis meses antes do evento, vimos a necessidade de fazer um logotipo para esse projeto, sendo assim, comissão executiva conversavam sobre a ideia do logotipo, posteriormente juntando-se a outros os sujeitos surdos e a equipe de produção de design, composta pela coordenadora Bruna da Silva Branco, o desenhista Arthur Fedrizzi e Bruna Branco, a Designer Helenne Sanderson, criaram uma logotipo do “Arte de Sinalizar". Ainda faziam parte da equipe, na gravação, os atores Douglas Faggion e Raoni Santos. Essa gravação foi realizada em locais públicos da cidade de Caxias do Sul/RS, apresentando o "Arte Sinalizar", com o intuito de divulgar o evento para a comunidade surda, incentivando-os a participar do Sarau.

Quanto ao vídeo de divulgação, de forma resumida, ele inicia com a cena dos amigos em um bar, que conversam e riem das piadas. Um deles, o ator Arthur Fedrizzi (que é o personagem principal), somente observa a cena, não expressa e não entende, não interpreta as conversas, somente observa sem comentar. Repentinamente, ele recebe uma mensagem de texto em seu celular, imediatamente, de forma muito educada se levanta, despede-se dos amigos com um gesto de tchau e sai apressado. Outra cena que faz parte do enredo, com outros atores, mostra uma mulher de costas, que troca apressadamente sua camisa e sai correndo do lugar. Outro homem que estava na parada do ônibus, logo percebe que não conseguiria aguardar, decidiu de supetão sair correndo, na cena é possível ver este mesmo homem correr no meio da trilha do trem. E outro personagem, um rapaz apressa-se a sair da porta da sua casa para então correr pela rua.

Finalmente todos chegam a determinado local. Enquanto as cenas se passam, todos na verdade assistiam um Sarau, muitas risadas, conversas sendo trocadas com emoção e alegria. Afinal, o Sarau Arte de Sinalizar envolve narrativa, humor e poesia

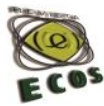

Revista Ecos vol.24, Ano 15, nº1 (2018) 
em língua de sinais. Para ver na integra o vídeo de divulgação do Sarau Arte de Sinalizar (2017) pode-se acessar o site do Arte de Sinalizar ou o site youtube ${ }^{\mathrm{iii}}$.

Além disso, tivemos a equipe do design, responsável na produção do cartaz, os ingressos para gráficas, entre os outros materiais. Também foram convidados a fazer parte da comissão, alguns colegas do curso de Letras Libras: Vanessa Harter, como atriz e parte da comissão, Marcelo Bertolucci (residente em Florianópolis-SC) que conduz o desenvolvimento do site - Arte de Sinalizar e um ator como integrante, convidado especial Itacir Carmo.

Em 24 de abril de 2017, foi realizado o primeiro "Sarau Arte de Sinalizar: narrativa, humor e poesia", que deu origem a eventos culturais desse porte e ainda, específico para a comunidade surda em Porto Alegre. Naquela ocasião, reuniram-se mãos e olhos dos espectadores em uma casa noturna da cidade para prestigiar o evento.

Ainda sobre o Sarau, este trata de uma das atividades do projeto, no qual muitos artistas surdos do Brasil são convidados a participar, profissionais ou não, em um evento aberto ao público. A atividade realizada ocorreu em parceira com a Conferência Nacional de Libras - Conali2017. Na ocasião do evento, ao finalizar as atividades do Conali2017, os participantes foram convidados a participar do Sarau Arte de Sinalizar.

O evento cultural contou com apoio da UFRGS, da Sociedade dos Surdos do Rio Grande do Sul - SSRS, da Confederação Brasileira de Desportos dos Surdos CBDS, do Grupo Interinstitucional de Pesquisa em Educação de Surdo - GIPES e da Conali2017. O patrocínio veio todo da Uníntese, uma instituição educacional com sede em Santo Ângelo-RS.

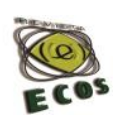

Revista Ecos vol.24, Ano 15, nº1 (2018) 
O palco contou com a presença de 23 surdos brasileiros, alguns são artistas e outros não, pois participam de forma voluntária e a partir de diferentes estados: Ceará, Rio Grande do Norte, Rio de Janeiro, São Paulo, Paraná, Santa Catarina e Rio Grande do Sul (deste, são 12 artistas). No Sarau Arte de Sinalizar não necessariamente todos que apresentavam eram artistas profissionais, mas de forma bem alegre recebíamos sujeitos surdos que através da comunidade surda tinham o interesse de compartilhar a herança do povo surdo, o que colaborou para a circulação, consumo e produção (KARNOPP; KLEIN; LUNARDI-LAZZARIN, 2011) das mãos literárias.

Quanto a organização do espaço e tempo no palco, cada artista dispunha de um tempo limitado, ou seja, cinco minutos para a apresentação, realizada em língua de sinais, destacando as mãos literárias. A atividade literária desenvolvida em Língua Brasileira de Sinais, objetiva, entre outros aspectos, dar ênfase às produções nesta língua, sem a presença de intérprete.

Inferimo-nos como autores das mãos literárias e como os artistas apresentar no palco. No espaço, quanto ao material, temos duas filmadoras para gravação, uma ficando atrás da plateia (mesas) e outra ao lado no corredor, além de mais dois surdos voluntários como fotógrafos: Prof. Ms. Nelson Goettert e Leandro Thome.

O espaço no Bar Pub Peppers contou com mais de 300 pessoas, reunindo mãos de artistas, convidados e comissão. A maioria dos presentes era bilíngue (Libras e Português), mas também estavam presentes alguns alunos e professores surdos e ouvintes da UFRGS. A maioria dos participantes eram de outros estados do Brasil, em função da parceria do Sarau com a Conali2017, organizado pela Federação Nacional de Educação e Integração dos Surdos - Feneis.

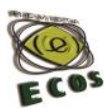

Revista Ecos vol.24, Ano 15, nº1 (2018) 
No espaço dos espectadores, onde ficavam as mesas e cadeiras, era importante que fosse um ambiente agradável, para que todos sentissem como se aquele lugar fosse o território das mãos. Os espectadores presentes, que contemplavam os sujeitos surdos, puderam perceber que ali era um lugar das mãos, um compartilhar entre os olhos e mãos, de bate mãos, de alegrias, risadas e muita emoção.

Algo possível de se perceber quando aos olhares dos espectadores, eram atraídos pelas mãos literárias, pareciam não conseguir desviar seus olhos, expressando a viagem literárias, mostrando sobre as descobertas das histórias, das narrativa, do humor e da poesia, tudo muito recheado de emoção, nos olhos e mãos, o que é próprio dos sujeitos artistas surdos, do pertencimento da cultura surda.

É possível assistir ao vídeo de seis minutos das mãos literárias, bem como fotos no espaço cultural, acessando o site do Arte de Sinalizar - 2017.

\section{Metodologia}

A metodologia envolve o uso do espaço cultural "Sarau Arte de Sinalizar; narrativa, humor e poesia.", como organizadores e parte constitutiva da comissão do evento e enquanto sujeitos surdos objeto destes estudos e, ao mesmo tempo, é possível se observar a interação no espaço entre os sujeitos surdos e ouvintes.

Após o encerramento, ainda no palco realizamos entrevistas com os espectadores de maneira presencial, no espaço cultural e no Conali2017, pois eram os mesmos que estiveram no sarau literário no dia anterior. Tendo como abordagem as entrevistas abertas (FLICK, 2009), facilitando que fossem manifestas 
espontaneamente, perguntando acerca da experiência pessoal no espaço do Sarau. Deixamos claro que poderiam ainda, acrescentar suas opiniões.

Antes da realização das entrevistas, explicamos sobre as filmagens que poderiam resultar em análises, artigos e divulgação na mídia, destacando que a pesquisa não envolveu riscos. Todos concordaram em participar das entrevistas, bem como de terem seus nomes publicados.

Após entrevistas concluídas, entramos em contato pelo e-mail, anexando a Autorização de uso de imagem, voz e respectiva cessão de direitos.

\section{Documentando os espectadores e análise...}

É fundamental desmarcar o problema de pesquisa, quanto aos espectadores, considerando sua constituição e experiência no momento do espaço sarau literário, que representa a Literatura Surda.

Analisamos um total de 59 entrevistas, sendo 54 entrevistas de surdos e 5 entrevistas de ouvintes. Ao analisar os sujeitos das entrevistas, a ênfase recai sobre o espaço cultural no sarau literário e constituição da experiência, que pode ser relevante e indicado por meio de um discurso ou uma narrativa.

Após as entrevistas filmadas e registradas, analisamos e reconhecemos a importância de um discurso, relacionado às experiências pessoais, que podem marcar e expressar, representar os elementos da cultura surda, relacionando aqui os estudos surdos e estudos culturais.

Durante análise da organização do material empírico e a realização das entrevistas sinalizadas, identificamos as suas constituições, opiniões e comentários,

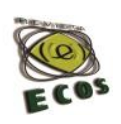

Revista Ecos vol.24, Ano 15, nº1 (2018) 
bem como suas percepções individuais, como se identificam e como é a sua expressão individual. Segundo Mourão (2017, p. 124) "Por meio dos sujeitos surdos, o que se passa, o que se toca e o que se vê da subjetividade é algo cuja base está nas mãos literárias, que constroem os significados e as formas de representação."

A partir daí, do total de entrevistados, escolhemos 34 entrevistas para divulgação dos vídeos, disponíveis no site do Arte do Sinalizar, com legenda em português elaborada pela tradutora e intérprete da língua de sinais, Profa. Ms. Luciane Bresciani. Para organização deste artigo, conseguimos 23 entrevistas, as quais foram alocadas em diferentes categorias, relacionando a temática. Quanto as outras entrevistas, são similares, apresentam características muito próximas, quanto aos elogios, emoção, o que compartilham uns aos outros, mãos literárias excelentes, desejamos que façam em momento oportuno novamente.

\section{A forma significativa do sarau}

Sabemos que não é ao sujeito surdo que falta informações, mas o problema sim está relacionado a limitação das informações e da educação por parte da sociedade e da massa que faz uso de recursos, de tecnologias, que utiliza as comunicações com livre acesso, massa que pode escutar o "som” do rádio, a música, sem problemas assistir à TV, conversar com as pessoas, participar sem dificuldades em eventos culturais, enfim a massa que se faz presente no território da língua oral "falada".

Dos entrevistados, havia os que pensavam que sarau era um tipo de show. Diante do espaço cultural presenciado, perceberam-se sentimentos diferentes, 
descobertas compartilhadas entre sujeitos e comunidade surda. Uma das entrevistadas, Flaviane Reis, de Minas Gerais, comenta:

Eu pensei que Sarau fosse um tipo de show com algumas coisas. Quando cheguei vi que era diferente e bem legal. (...). Eu fiquei pensando... não era um show? Comecei a perguntar e as pessoas me disseram que não era show. Sarau é um espaço para bate papo, narrativas, poesia, teatro... diferentes produções que são compartilhadas ao mesmo tempo. Enquanto as pessoas bebem elas assistem as apresentações e interagem. Então, eu entendi o significado de sarau.

Quando cheguei no local ontem, não imaginava o que aconteceria. Pensei que fosse um show, mas não. Eram apresentações em língua de sinais, então fiquei emocionado. (Marcos Vinni-Minhas Gerais)

Outro entrevistado, Marcelo Amorim também comenta sobre a importância deste evento do sarau;

Qual a importância deste evento? Porque representa o primeiro passo, pois muitos desconheciam o que seria um SARAU, não conheciam o significado de um sarau. Mas o que é? Com as apresentações ficou claro. É importante porque não estávamos acostumados com outro tipo de eventos, encontros com palestras realizadas em auditórios, congressos... lugares que exigem outra postura. Vivenciamos algo diferente, uma atividade organizada em um bar com bebida, rodas de bate papo... $O$ que é isso significa? Nos ambientes onde ocorrem os congressos, por vezes nos sentimos restritos. Em um bar nos sentimos mais abertos e nos expressamos com maior facilidade.

No território surdo, como no espaço das mãos, a língua de sinais, os olhos transmitem emoções, significativas, emergem as expressões compartilhadas um com o outro. Conforme Klein (2005) e Souza (1998) destacam, que a língua de sinais é uma

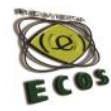

Revista Ecos vol.24, Ano 15, $n^{\circ} 01$ (2018) 
das principais razões de encontro entre os surdos, pois é através da experiência de compartilhar uma língua de modalidade gestual-visual que eles têm oportunidades de trocar experiências, conversar, aprender. (KARNOPP, 2010, p. 157).

No espaço cultural, se produz uma fabricação da visualiterária, como se fosse leitura dos livros. Bianca Pontin (Rio Grande do Sul) comentou a entrevista, sinalizou que o sarau precisa se repetir.

(...) acredito que atividades como essa precisam de repetir, trata-se de um momento para encontros e bate-papo, diálogo e expressão natural. Mas é como a leitura de um livro. O livro pode me trazer satisfação, assim como outro. Esse encontro com a língua de sinais pode se repetir. Onde os espectadores podem se sentir provocados a apresentar em outro. Às vezes o que é sinalizado, pode despertar em mim a vontade de sinalizar. Vamos ver o quanto isso de ampliar e se expande. similar:

Outra entrevistada, Helenne Sanderson (Rio Grande do Sul) comenta algo

A língua de sinais na expressão e no compartilhamento, do riso e da tristeza. A emoção circulando como na leitura de um livro, com parte em que você sorri... uma leitura fluída. Sabemos que a leitura é importante para ampliar o nosso conhecimento. $O$ mesmo ocorre com o sarau, mas com a produção em língua de sinais.

Visualiterária traduz de forma significativa as manifestações literárias, que se transformam, numa viagem imaginada ao território de conhecimentos. Segundo Mourão (2016, p. 150) "a transformação pela experiência pode ser transmitida no espaço das "leituras" da língua sinalizada". Neste sentido, nos sujeitos surdos há mãos literárias, no espaço e palco, produzem subjetividade e transformam as páginas na

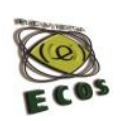

Revista Ecos vol.24, Ano 15, nº1 (2018) 
forma de histórias, de personagens e de experiências de mãos, torna-se fábricas literárias dos sujeitos surdos.

(...) As poesias e piadas contadas são fruto das experiências que cada um apresentou. Diferentes formas e conhecimentos surdos que foram absorvidos, internalizados. São as experiências que tem um pouco da vida de cada sujeito. Cada história contada a experiência do outro, como um espelho. O que era apresentado se tornava divertido pois as pessoas se reconheciam naquelas histórias. Histórias tristes nos comoviam porque provocavam a reflexão. Foi um momento extremamente importante e espero que venha outras edições. (André Reichert - Santa Catarina)

A língua implica cultura (STOKOE, 2006), a comunidade surda é bilíngue (WILCOX e WILCOX, 2005), por meio da comunidade surda que habita o território nacional, construímos o orgulho de ser brasileiro. Como sujeitos de outras manifestações culturais e identitárias nos constituímos bilíngues e biculturais e o pertencimento à comunidade surda potencializa manifestações literárias específicas que inferem nos processos de subjetivação. São assim, organizados modos de vida inscritos na possibilidade do visual e do gestual - marcas das experiências culturais surdas.

\section{A forma a identificação}

Um espaço é um lugar em nosso território surdo, é um lugar onde não há conflitos, não há interrupção, não há ausência de comunicação, não há ambientes desagradáveis, simplesmente é um espaço de uso em língua de sinais e da cultura surda, logo a língua conecta a cultura. A língua é um sistema social e não um sistema individual (Hall Stuart, 2011). Segundo Bauman (2017, p. 49) “o desejo de se apropriar



Revista Ecos vol.24, Ano 15, $n^{\circ} 01$ (2018) 
do seu próprio espaço está profundamente incorporado à Cultura Surda.” Conforme das entrevistas comente sobre um espaço surdo:

Ontem no evento estava no meu mundo. Um lugar no qual me diverti com as histórias, poesias, narrativas e piadas. Uma infinidade de emoções, boas e ruim, complexas e simples... diferentes. Não tem como explicar. Não tenho palavras para descrever a Literatura Surda. (Rimar Segala - São Paulo)

Não havia no Brasil. Na verdade haviam produções mais informais... em escolas... mas sem essa visibilidade. É um momento especial! Um momento visual da cultura surda. Espaço interação... Piadas, poesias e narrativas compartilhadas. (Mariana Campos São Paulo)

A primeira vez na história da minha vida. Nunca havia visto nada igual. No Rio tem muita produção, mas aqui em Porto Alegre. O Sarau... Não tem como explicar tamanha emoção. Fiquei emocionado! Um lugar especial para os surdos. A maioria das pessoas eram surda, poucos ouvintes. (Wendel de Oliveira - Rio de Janeiro)

Me senti conectada com as histórias contadas. Senti como se todas as mãos sinalizassem em sintonia. (Juliana Emmert - Rio Grande do Sul)

Como um sonho, que de repente eu estava vivenciando... Uma emoção... ver todas aquelas histórias narradas... estar naquele ambiente... no qual as pessoas narravam histórias reais. Foi muito bom! (Vinicius Pedroni-Paraná)

Podemos nos certificar que um espaço no território das mãos literárias, é um espaço lúdicos, de liberdade e viagens, de imaginação que transforma a identificação da cultura surda. Não é procurar uma propriedade escrita, nem narrar-se como dominante da língua oral, mas sim considerar o fato que podem, em muitos momentos terem sido limitados, dificultando a compreensão da interpretação das escritas literárias

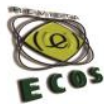

Revista Ecos vol.24, Ano 15, $n^{\circ} 01$ (2018) 
e da língua oral nos eventos culturais, o que fez com que os surdos sentissem sede da língua, que necessitassem de um encontro de surdos, virar uma página para o novo das mãos literárias. Segundo Kyle; Woll, (1985, p. 21, apud KARNOPP, 2010) não significa "Eu quero ser surdo", mas antes: "Eu sou uma pessoa surda e desejo estar em contato com outras pessoas que compartilhem minha língua."

O Sarau foi perfeito e combina muito com a cultura brasileira. Eu nunca havia visto nada como isso no Brasil. Já tinha observado em outros países... como piadas, pequenas histórias... diferentes apresentações. Mas faltava isso para o Brasil. A ideia do Cláudio em organizar esse projeto dentro da UFRGS ficou perfeito, aproveitando também a realização do CONALI... Essa atividade cultural ficou perfeita! (Ana Regina Campello - Rio de Janeiro)

Nossa! Foi um momento muito importante e que me marcou. Nunca havia vivido uma experiência assim no Brasil. Nunca tivemos um evento como esse em nossa história. É a primeira vez e fico pensando na importância disso. Este evento serve como modelo para o desenvolvimento de outras ações. (Rodrigo Machado - Ceará)

\section{A forma no espaço do outro}

Um espaço é constituído por questões que se identificam, num processo significativo, do qual somos pertencentes a determinado lugar e não a qualquer outro. Isso não significa separar-se algo, mas sim deleitar-se na sensação advinda do lugar, a que nos identificamos nele, experiências, olhares que se conectam às mãos, um processo subjetivo ao literário. Segundo Woodward (2014, p. 56) (...) nós vivemos nossa subjetividade em um contexto social no qual a linguagem e a cultura dão

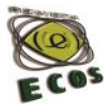

Revista Ecos vol.24, Ano 15, nº 01 (2018) 
significado à experiência que temos de nós mesmos e no qual nós adotamos uma identidade.

A poesia que apresenta a identidade surda. Já havia visto várias apresentações de ouvintes... narrativas..., mas agora em língua de sinais, maravilhoso! (Pedro Serafim - Santa Catarina)

Os ouvintes têm uma série de eventos, que emocionam, que comovem, com poesias e outras produções, como SLAM e outras atividades. É a primeira vez que participo de uma atividade para os surdos em língua de sinais. (João Gabriel - Santa Catarina)

Não tenho palavras para explicar o que senti no sarau ontem. Fiquei admirado com o que vi. Já havia sido convidado para participar de outras atividades com os ouvintes, mas me tocou de outra forma. Nos outros eventos eu conversava com as pessoas, mas sem muito entusiasmo. Pois se tratava de uma experiência diferente da vivenciada com os surdos. (...) quando vou aos shows de ouvintes eu não compreendo nada, em algumas ocasiões tem intérprete. Naquelas locais não entendo, mas ontem estive em um espaço valorizado. (Marcos Vinni - Minhas Gerais)

Sempre nos encontramos em bares, mas dessa vez foi diferente. (...) Identificando cada uma das histórias. Com muita satisfação. Na sociedade, incluídos, faltam essas sensações. Mas assistir às narrativas me alegraram muito. (Raoni Santos - Rio Grande do Sul)

É comum o que se encontra em eventos culturais do "outro", e o que comumente se tem é a impressão que algo está faltando para completar o espaço. Cito aqui, parte da entrevista realizada com atriz Fernanda Machado, destacando sobre a quantidade de peças presentes no evento cultural?

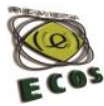

Revista Ecos vol.24, Ano 15, $\mathrm{n}^{\circ} 01$ (2018) 
Fiquei admirada com tudo aquilo que vi. Me emocionei porque estava realmente feliz com o que via. Sabem por quê?? Quantas peças teatrais são produzidas? Todos os dias! Quantas produções poéticas? Todos os dias! Quantas narrativas? Todos os dias! Quantas piadas são contadas? Todos os dias! É imensa a produção diária de tudo isso... Mas dos surdos em língua só tivemos ontem... um único dia. Isso demonstra a grandeza do evento. Quero que momentos como aquele sejam diários... Estava maravilhoso! (Fernanda Araújo - Santa Catarina)

Ainda existe o sujeito, o "outro", o ouvinte, que participa e que compartilha com sujeitos surdos em interação com comunidade surda. A autora Karin Strobel (2008, p. 31) comenta e conceitua a comunidade surda, “(...) a comunidade surda de fato não é só de sujeitos surdos, há também sujeitos ouvintes - membros de família, intérpretes, professores, amigos e outros - que participam e compartilham os mesmos interesses em comuns em uma determinada localização."

Em entrevista, Tiago Nogueira, que é professor e intérprete também comenta sobre o espaço sua percepção:

Fui ao Sarau e fiquei muito contente mesmo. Porque é era espaço de circulação da língua de sinais. Um lugar onde todas as pessoas estavam sinalizando. Existiam alguns, muitos poucos, que utilizavam a língua oral... mas muitos em língua de sinais. Logo que entrei senti que era diferente... todo aquele movimento da língua de sinais. Minha esposa estava comigo. Ela é ouvinte e sabe um pouco de língua de sinais. Ela se sentiu diferente! Está acostumada a ir em locais onde a maioria do público é ouvinte... e os surdos são minorias sinalizante. Mas desta vez foi diferente. Muitos surdos! Ela ficou um pouco perdida... disse que era muito legal aquele espaço com muitas pessoas sinalizando. Interessante e diferente! Foi assim que ela se sentiu.

O Sarau Literário é um espaço aberto público, não somente para os sujeitos surdos, ali circularam sujeitos ouvintes também. Eles estavam lá para prestigiar as mãos

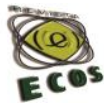

Revista Ecos vol.24, Ano 15, nº1 (2018) 
literárias, talvez a razão fosse por curiosidade, ou por conta do curso ou disciplina de Libras, são professores/pesquisadores, talvez sim e talvez não, podiam estar lá para pelo simples fato de estarem, sentindo e/ou buscando interação, conhecimentos e/ou aprender através do contato a língua própria dos surdos.

\section{A forma da produção significativa}

Um espaço de produção é um espaço literário significativo, que provoca e firma as marcas das mãos literárias, assimila os conhecimentos no campo da arte e da cultura, traduz o que precisa ser identificando, permite interpretar os efeitos literários mais profundos. Segundo Rachel, Sutton-Spence, entre outros (2016, p. 82) "a arte também é responsável pelo desenvolvimento da autoestima do sujeito. Sentir-se parte, pertencente a um povo e uma comunidade, contribui para um desenvolvimento emocional saudável."

Um espetáculo apresentado pelas mãos literárias é traduzido e interpretado dessa forma, cito entrevista:

uma apresentação que me tocou...uma poesia triste... aquela do abraço... me fez chorar, nunca havia me emocionado dessa forma, como a poesia conseguiu provocar tamanha emoção? (Rodrigo Machado - Ceará)

Percebemos de forma precisa a ausência do significado das artes e das literaturas, incluindo outros eventos culturais. Em determinados momentos, onde os sujeitos surdos têm se constituído no território das artes e da cultura, mas com barreiras impostas ali, permitindo que se sintam incompletos, pois permanecem, surdos isolados,

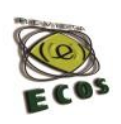

Revista Ecos vol.24, Ano 15, nº1 (2018) 
numa linha tênue do horizonte. Para elucidar o termo surdo isolado, Coelho e Cortez, (2013, p. 391) ponderam:

(...) uso do termo isolado não significa que estes indivíduos se encontram afastados de outros seres humanos e da sociedade, a utilização deste termo significa apenas uma situação de isolamento linguístico devido à falta de contacto com uma língua comunitária, seja LGP ou LP ${ }^{\mathrm{iv}}$.

As entrevistas trazem essa relação, a ausência da arte e da cultura, neste sentido das barreiras, a qual não consegue permear a interpretação cultural, nem sequer produzir os efeitos significativos literários. A linguagem literária está em primeiro plano (Quadros; Rachel 2006), sendo que as funções principais ao se oferecer o acesso ao ser humano na sua subjetividade, a possibilidade que a literatura configura permite abrir as portas para esse mundo, literatura que faz parte da sua cultura, é a língua de sinais que transmite a sensação do estado da arte e da cultura.

(...) porque não estamos acostumados com esse espaço cultural, crescemos sem essa expressão poética era difícil esse contato com a arte, pouca poesia. Por isso esse momento serve como um estimulo. (Rodrigo Machado - Ceará)

Um encontro de bar oportuniza a sensação de lazer, é um momento onde há compartilhamento literário, as mãos se abrem numa imensidão de expressões literárias, que produzem deste um espaço de cultural, experiência que traduz a arte de sinalizar. Nesse sentido da experiência, a arte está "entre" a obra e o espectador, segundo Jorge Larrosa (2010) $)^{\mathrm{v}}$ : 
(...) É importante porque não estávamos acostumados com outro tipo de eventos, encontros com palestras realizadas em auditórios, congressos... lugares que exigem outra postura. Vivenciamos algo diferente, uma atividade organizada em um bar com bebida, rodas de bate papo... O que é isso significa? Nos ambientes onde ocorrem os congressos, por vezes nos sentimos restritos. Em um bar nos sentimos mais abertos e nos expressamos com maior facilidade. (Marcelo Amorim - Ceará)

(...) foi minha primeira experiência, mas percebo a oportunidade para área da Literatura. Eu adorei! Porque estamos acostumados a participar de vários congressos... ano após ano. Sinto que falta arte. Começamos a abrir esse espaço para participação das pessoas. As palestras são com sal... nos faltava o doce... Esse momento no bar é como se fosse um doce. Nos divertimos... gostei muito desta experiência. Espero que que não pare. Que venham outros e outros Saraus. (Isaack Saymon - Rio Grande do Norte)

\section{A forma a registrar}

O projeto Arte de Sinalizar impulsiona, da ênfase ao registro das produções das mãos literárias pelo povo surdo, ao que está circulando, sendo consumido e produzido através da sinalidade, embora não registrado. (KARNOPP, 2006; ROSA; KLEIN, 2011, SILVEIRA, 2015, NICOLS, 2016, MOURÃO, 2016).

Em uma parte da entrevista se comenta sobre registro:

(...) O compartilhamento e produção da arte na comunidade surda... é de extrema relevância. Porque muito surdos, ao longo da história, não tem o registro destas produções. (Carilissa Dall Alba - Rio Grande do Sul)

$\mathrm{Na}$ Universidade de Gallaudet (University Gallaudet) existe uma biblioteca para os acadêmicos surdos, em Washington, nos Estados Unidos da América e de

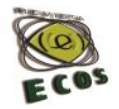

Revista Ecos vol.24, Ano 15, nº 01 (2018) 
acordo com Oliver Sacks (1998, p. 37), esta é “[...] a única faculdade de ciências humanas do mundo para alunos surdos - embora existam agora vários programas e institutos para surdos associados a faculdades de áreas técnicas. Um destaque importante da entrevista, faz menção ao intercâmbio realizado em 2011, na Universidade de Gallaudet, onde estive estudando e pesquisando na biblioteca, e que havia vídeos em VHS registrados, em inúmeras gêneros literários da Língua de Sinais Americana (ASL - American Sign Language):

Quando estive na Gallaudet, em 2011 (...), fiquei emocionada pois estive na biblioteca da universidade, era uma quantidade imensa de materiais nas antigas fitas de VHS. Era uma grande quantidade de apresentações de surdos, apresentando suas poesias, narrativas e piadas. Tratava-se de uma variedade de produções e eu fiquei boquiaberta. Como se me nutrisse daquelas produções... querendo sempre mais. Delicioso assistir tudo aquilo. Eu pensava... no Brasil não tem. Queria ver sempre mais aquelas produções... até que não havia mais o que assistir. (Carolina Pego - Santa Catarina)

Existem materiais publicados da Literatura Surda Brasileira, impressosdigitais e vídeos, mas não em grande quantidade e ainda de pouca circulação, um exemplo são as filmagens realizadas na produção tanto e ainda circular que foram filmadas da produção das mãos literárias, temos como exemplo as redes sociais. A entrevistada Carolina Pego, diz ainda que ao retornar para o Brasil, acreditava não encontrar aqui um espaço cultural, particularmente em língua de sinais.

Retornei ao Brasil ficava pensando a necessidade de espaço para os surdos... quem sabe no futuro pudesse organizar algo... Mas não é que Cláudio e sua equipe tiveram a ideia de organizar um Sarau. Fiquei pensando: será igual ao que havia visto em Gallaudet? Já frequentei diversos locais... diferentes de Gallaudet. Mas quando

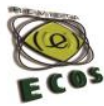

Revista Ecos vol.24, Ano 15, nº1 (2018) 
cheguei aqui... fiquei boquiaberta! Era ao vivo! Eu tinha visto em VHS, mas ao vivo a emoção foi extraordinária! Narrativas e outras apresentações que não tem como explicar. Foi emocionante ver as apresentações ao vivo. (Carolina Pego - Santa Catarina)

Outra entrevistada comenta que acreditava ver nesse espaço poucas pessoas, bem diferente do que pode experienciar, conforme relata:

Eu pensava que seria em um lugar simples, com poucas pessoas... por causa de outras experiências. Mas foi muito diferente! O espaço estava lotado! Com Luzes... foi muito forte! Não tem como explicar... (Mariana Campos - São Paulo)

No Brasil, o avanço de registro se deve a "tecnologia", agora temos a possibilidade de filmar/vídeo, sobre Literatura Surda Brasileira. Registros esses imprescindíveis à sobrevivência do patrimônio das mãos literárias do povo surdo. Segundo Carolina Silveira (2015, p. 16), torna-se crucial, em nossos dias, o "uso de registros visuais, como as fotos e filmagens, que funcionavam como importante patrimônio histórico-cultural das comunidades surdas".

(...) Agora temos a oportunidade de apresentar e registrar essa história. A comunidade surda poderá acessar essas produções nos meios digitais... ou poderam ter essas produções em formato de filme. (Carilissa Dall 'Alba - Rio Grande do Sul)

(...) Por sorte todas as apresentações foram filmadas, isso me deixou muito feliz. Pois no futuro as crianças poderão se emocionar assim com eu quando assisti. (...). Precisamos de mais atividades como essa. Para que outras pessoas, assim como eu, possam aproveitar. As crianças precisam destes registros. (Carolina Pego - Santa Catarina)

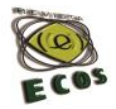

Revista Ecos vol.24, Ano 15, nº 01 (2018) 
(...) E isso é importante enquanto registro, que esse primeiro passo se multiplique em outros tantos eventos, que podem ocorrer em diferentes regióes do país, filmando e registrando para publicar. (Marcelo Amorim - Ceará)

\section{A forma ininterruptamente piscar dos olhos}

Este é um espaço em que permanecemos estáticos, sem piscar dos olhos, sem desviar a direção do olhar do palco, diferente do que era recorrente em outros momentos, olhos 'secos', percepções insignificantes. Diferente então quando nesse momento se olha pela "visualiterária", quando surgem os efeitos literários significantes. Tatiane Ledebeff (2017, p. 2013) comenta sobre os olhos, seu objetivo: "E é somente pela visão que o surdo alcançará esses objetivos. Assim, ele conseguirá significar o mundo em que vive, pois passa a entendê-lo por meio de seus olhos." Dentre os entrevistados, destaca-se a centralidade dos olhos atentos e vidrados:

(...) Todos estavam atentos... sem perder nenhum detalhe, interessados pelo que estava acontecendo no palco fixados no que acontecia... seriam incapazes de perceber a presença de uma mosca, muito menos de matá-la. Olhos vidrados... conectados de fato com os artistas. (Bruno Ramos - Rio de Janeiro)

(...) Eu pensei que os surdos ficariam batendo papo, pois estávamos em bar..., mas não foi isso que aconteceu. Todos estava atento às informações que eram sinalizadas. Poesias... Teatro... Os surdos assistiam atentos sem nada de bate-papo. Vidrados do início ao fim. Fiquei emocionada... foi algo muito diferente, não existia algo assim. (Luciana Vaz-Rio Grande do Sul)

Se eu conversei com as pessoas? Não! Fiquei atento as apresentações. Rindo com as piadas... Nunca tinha visto nada igual na minha vida. Um ESPETÁCULO! (Wendel de Oliveira - Rio de Janeiro)

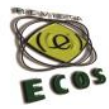

Revista Ecos vol.24, Ano 15, nº 01 (2018) 
Para finalizar refletimos sobre a forma dos espaços da necessidade de ressignificar as marcas surdas que foram subjetivas no espaço cultural. São eles, os sujeitos surdos que nas "entrevistas" seguiram narrando sua experiência, expuseram seus sentimentos, expressando a emoção, respirando e contemplando, se envolvendo da Literatura Surda Brasileira.

\section{As mãos literárias não terminam aqui.}

O primeiro Sarau Arte de Sinalizar entrou para história da comunidade surda brasileira. Foi uma surpresa perceber que o espaço no Bar Pub Peppers estava lotado e vibrante com tantas mãos. Inclusive, haviam sujeitos nas filas de espera na porta, visivelmente seus rostos mostravam pelas suas expressões o quanto aquele lugar estava chamando a atenção, pareciam torcer o pescoço para conseguir olhar. Outra questão importante a se destacar desse primeiro Sarau, foram os elogios recebidos por parte do espaço cultural, por vivenciarem e compartilharem aquele momento com o povo das mãos.

As entrevistas sinalizadas tornam-se relevantes, os depoimentos nos permitem mostrar os resultados das experiências do outro, registrar e conectar, ter um fluxo da Literatura Surda. E entrevistas sinalizadas contaram que jamais imaginaram encontrar um espaço 'surdo', pois eles estão acostumados a ambientes com a presença de surdos e ouvintes, mas que comumente a maioria é ouvinte. No entanto, este evento se constituiu em um espaço surdo, onde as pessoas se sentiram em um ambiente agradável, de mãos literárias compartilhadas.

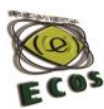

Revista Ecos vol.24, Ano 15, nº 01 (2018) 
Podemos perceber "as formas" no espaço, os espectadores e suas subjetividades entre as mãos literárias as diferentes de conceber e transformar a sua experiência. Neste sentido, o espaço traz significativa literária, abarca a Literatura Surda.

As produções do Sarau foram registradas através de fotos e vídeos com o objetivo de divulgar as mãos literárias como uma biblioteca virtual, no site arte de sinalizar.

Para além deste evento Sarau Literário, as pessoas que dele participaram carregam em seus olhos a lembrança das mãos literárias, deixando marcas na história das mãos de artistas surdos e do espaço surdo. Para finalizar este artigo, anunciamos que haverá outro artigo, no qual pretendemos analisar e compartilhar o que foi apresentado pelos artistas surdos brasileiros.

Para ver a lista completa dos artistas surdos presentes no Sarau Arte de Sinalizar: narrativa, humor e poesia - 2017 veja abaixo:

\section{Mãos de Rio Grande do Sul}

André Paixão

Arthur Fedrizzi

Bruna Branco

Carlos Alberto Goes

Carolina Hessel

Cláudio Mourão

Douglas Faggion

Emiliana Rosa

Francisco Rocha 
ISSN: 2316-3933

Online

Gisele Rangel

Itacir Carmo

Raoni Santos

Mãos de outros estados

Bruno Ramos - Rio de Janeiro

Clarissa Fonseca - Rio de Janeiro

Daltro Junior - Santa Catarina

Francisco Terceiro - Paraná

Isaack Saymon - Rio Grande do Norte

Luana Marquezi - Santa Catarina

Mariana Campos - São Paulo

Marcelo Amorim - Ceará

Rimar Segala - São Paulo

Victoria Pedroni - Santa Catarina

Wendel de Oliveira - Rio de Janeiro

Notas:

${ }^{\text {i }}$ Disponível em: <https://www.dicio.com.br/sarau/>. Acesso em: 23 maio 18.

ii Disponível em: <https://saraubenedito.wordpress.com/o-que-e-sarau/>. Acesso em: 21 maio 2018.

iiisite do Arte de Sinalizar, disponível em: <https://www.ufrgs.br/artedesinalizar/> e vídeo <https://youtu.be/1nQIduYfX1k>. Acesso em: 21 mai. 2018.

iv LGP - Língua Gestual Portuguesa / "Língua gestual” é a denominação utilizada por Portugal, diferente do Brasil, que utiliza "língua de sinais" e LP - Língua Portuguesa

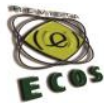

Revista Ecos vol.24, Ano 15, nº1 (2018) 
ISSN: 2316-3933

Online

v Blogueira da JAJA. Disponível em:

$<$ https://jajagalant.wordpress.com/2013/08/19/resenha-do-artigo-notas-sobre-aexperiencia-e-o-saber-de-experiencia-de-jorge-larrosa-bondia-traducao-e-joaowanderley-geraldi/>. Acesso em: 29 jan. 2019.

\section{Referências}

BAUMAN, Hansel. DEAFSPACE: visão para uma arquitetura mais centrada no humano. In. Letramento Visual e Surdez. LEBEDEFF, Tatiana; et al. (org.). Rio de Janeiro: Wak Editora, 2017.

COELHO, Orquídea; CORTEZ, Susana. Surdos Isolados, Línguas, Cidadania, Identidade e Iliteracia. In: COELHO, Orquídea. KLEIN, Madalena (Coord.). Cartografias da Surdez: Comunidades, Línguas, Práticas e Pedagogia. [et al.]; colab. Sara Sousa, Cátia Lopes, Francisco Neves. Porto: Livpsic, 2013.

HALL, Stuart. A identidade cultural na pós-modernidade. 11. edição, 1. Reimp. Tradução: Tomaz Tadeu da Silva, Guaracira Lopes Louro, Rio de Janeiro: DP\&A, 2011.

FLICK, Uwe. Introdução à pesquisa qualitativa. Porto Alegre: Artmed, 2009.

GOLDEMBERG, Deborah. A Concepção do I Sarau das Poéticas Indígenas por uma Antropóloga-Escritora. Espaço Ameríndio, Porto Alegre, v.3, n. 1, p. 42-60, jan./jun. 2009.

GOLDEMBERG, Deborah; CUNHA, Rubelise. Literatura Indígena Contemporânea: o encontro das formas e dos conteúdos na poesia e prosa do I Sarau das Poéticas Indígenas. Espaço Ameríndio, Porto Alegre, v. 4, n. 1, p. 117-148, jan./jun. 2010.

KARNOPP, Lodenir. Produções culturais de surdos: análise da literatura surda. In: VIEIRAMACHADO, Lucyenne; LOPES, Maura (orgs.) Educação de Surdos: políticas, língua de sinais, comunidade e cultura surda. 1 ed., Santa Cruz do Sul: EDUNISC, 2010.

LARROSA, Jorge. Tremores: escritos sobre experiência. Tradução Cristina Antunes, João Wanderley. 1 ed. reimp. - Belo Horizonte: Autência Editora, 2015.

MOURÃO, Cláudio. Literatura Surda: produções culturais de surdos em Língua de sinais. Porto Alegre, 2011. 132 f. Dissertação de mestrado - Programa de pósgraduação em Educação - Universidade Federal do Rio Grande do Sul. Faculdade de Educação. Porto Alegre, 2011. 
ISSN: 2316-3933

Online

Literatura Surda: experiência das mãos literárias. 2016, 287 f. Tese (Doutorado em Educação). Faculdade de Educação, Universidade Federal do Rio Grande do Sul, Porto Alegre, 2016.

SACKS, Oliver. Vendo vozes: uma jornada pelo mundo dos surdos. Tradução Laura Texeira Motta. - São Paulo: Companhia das Letras, 1998.

SILVEIRA, Carolina Hessel. O currículo de Língua de Sinais na Educação de surdos. Dissertação de Mestrado em Educação - Universidade Federal de Santa Catarina, 2006. STOKOE, Willian. Língua gestual como primeira língua da humanidade. In. O Gesto e a Palavra I: antologia de textos sobre a surdez. BISPO, Maria; COUTO, André; CLARA, Maria; CLARA, Luís (org.). Ed. Caminho, AS, Lisboa, 2006.

SUTTON-SPENCE, Raquel; [et al.]. Os craques da Libras: a importância de um festival de folclore sinalizado. Revista Sinalizar, v. 1, p. 78-92, 2016.

WILCOX, Sherman \& WILCOX, Phyllis Perrin. Aprender a Ver. Petrópolis, RJ, Editora Arara Azul, 2005.

WOODWARD, Kathryn. Identidade e diferença: uma introdução teórica e conceitual. In: SILVA, Tomaz Tadeu (org. e trad.). Identidade e diferença: a perspectiva dos estudos culturais. $14^{\circ}$ ed. Petrópolis: Vozes, 2014.

Este texto é de total responsabilidade de seus autores. 